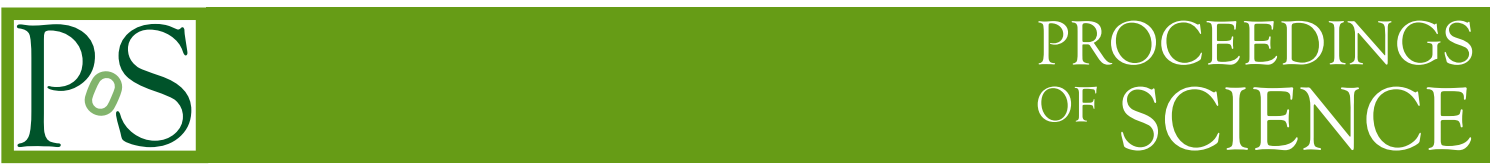

\title{
Kurt Gödel philosopher: from logic to epistemology
}

\author{
Gabriella Crocco* \\ CEPERC UMR 7304, Aix-Marseille Université \\ E-mail: gabriella.croccoduniv-amu.fr
}

\begin{abstract}
Kurt Gödel left Philosophical Remarks in his Nachlass that he himself entitled Max Phil. The opus originally comprised 16 notebooks but one has been lost. The content is on the whole the outline of a rational metaphysics that allows us to relate the different academic disciplines to each other and in particular logic, mathematics, physics, biology and theory of knowledge.

The notion of time is most interesting for Gödel because it is a subject that connects humanities with the sciences. Therefore he engages with it quite often and quite intensely. This is also true for the concept of force. His transdisciplinary approach is to contemplate 'force' as a notion in physics (gravitation and quantum mechanics), as a notion in psychology (affects and emotions) and as a notion in biology, albeit he has a specific interest in physics concerning the concept of force. He is looking for an interpretation of the concept that would allow him to align the theories of relativity and quantum mechanics. Besides that the preoccupation with light quantum gives Gödel an opportunity to reflect on the differences between light and matter. We will present the main structure of Max-Phil, which as been partially transcribed and translated by a international team funded by the ANR project BLA -09-13 and focus on some remarks concerning the relationship between mathematics and physics.
\end{abstract}

Frontiers of Fundamental Physics 14 - FFP14,

15-18 July 2014

Aix Marseille University (AMU) Saint-Charles Campus, Marseille

\footnotetext{
*Speaker.
} 